\title{
Leaf geometric morphometric analyses of Callicarpa and Geunsia (Lamiaceae) in the Malesian region
}

\author{
JENNIFER S. DANILA ${ }^{1, \vartheta}$, GRECEBIO JONATHAN D. ALEJANDRO ${ }^{1,2}$ \\ ${ }^{1}$ The Graduate School, University of Santo Tomas. España Blvd., 1015 Manila, Philippines. `email: jennifer.danila.gs@ust.edu.ph \\ ${ }^{2}$ College of Science and Research Centre for the Natural and Applied Sciences, University of Santo Tomas. España Blvd., 1015 Manila, Philippines
}

Manuscript received: 8 August 2021. Revision accepted: 24 September 2021.

\begin{abstract}
Danila JS, Alejandro GJD. 2021. Leaf geometric morphometric analyses of Callicarpa and Geunsia (Lamiaceae) in the Malesian region. Biodiversitas 22: 4379-4390. Leaves are one of the most substantial organs of plants for it serves as a basis of species identification. Leaf morphology provides distinguishing features that help in the discrimination of plant species as well as investigation of leaf features among populations. This study aimed to investigate leaf shape variations between the two genera Geunsia Blume group and its closely related taxon, Callicarpa L. (Lamiaceae) using a landmark-based geometric morphometric method. The differences in the leaf shape among former members of Geunsia, namely $C$. apoensis, C. basilanensis, $C$. flavida, C. paloensis, $C$. pentandra, $C$. ramiflora, and $C$. surigaensis are also evaluated. Two primary landmarks and 14 semilandmarks were assigned in all samples to represent changes around the leaf margin. The Procrustes fit was generated using MorphoJ software which displays the mean and landmark position for individual configurations. Canonical Variate Analysis (CVA) and Mahalanobis Distance (MD) were able to discriminate all samples of Geunsia species using a scatter plot. Furthermore, Procrustes ANOVA showed a significant difference $(P=$ 0.0082) among the seven species of the Geunsia group. Based on the results obtained, geometric morphometrics of leaf shape is effective in interspecific discrimination within members of Geunsia. However, the result of Discriminant Analysis (DA) showed that Geunsia and Callicarpa groups made leaf shape differences inefficient in discriminating the two genera. Therefore, further morphological studies on landmark-based geometric morphometrics of leaf shape involving a larger number of samples especially in the study of intergeneric classification are suggested.
\end{abstract}

Keywords: Callicarpa, Canonical Variate Analysis, Geunsia, landmark, leaf shapes, mahalanobis distance, procrustes analysis

\section{INTRODUCTION}

The taxonomy between Callicarpa L. and Geunsia Blume was among the most controversial genera in the family Lamiaceae (Bramley 2009). Since Geunsia was described by Blume (1823), members of the group have been known as synonyms of several Callicarpa species. Currently, Geunsia is regarded as a synonym of the genus Callicarpa (Cantino 1992; Harley et al. 2004; Bramley 2009; IPNI 2021; POWO 2021) based on the examination of morphological characters (Lam and Bakhuizen van den Brink 1921; van Steenis 1967; Govaerts et al. 2007) and molecular data (Bramley 2009). However, several rejections of previous characters (Lam 1919; Lam and Bakhuizen van den Brink 1921; Ridley 1923; Moldenke 1982) continue to challenge the relationship of the two genera.

The most widespread, $C$. pentandra Roxb. together with other former members of the Geunsia group, namely C. basilanensis Merr., C. flavida Elmer, C. ramiflora Merr., C. surigaensis Merr., and $C$. apoensis Elmer led to a complicated taxonomic relationship between Geunsia and Callicarpa (Bramley 2011). The inclusion of several species like $C$. pentandra and its affinities in the genus Callicarpa led to a complex species classification whether to separate conspecific species or retain its infraspecific classification. According to Lam (1919), species of Geunsia can be distinguished through leaf arrangement, conspicuous ridge in the petioles, anthers opened by widening of the upper part of the parallel fissures, and the ovary (three-)five-celled, the cells are two seeded. However, the circumscription of the genus Geunsia remains uncertain due to overlapping characters (Lam 1919; Bramley 2009; Danila and Alejandro 2020). The members of Geunsia in the Philippines as having similar features to the three varieties of $C$. pentandra based on indumentum but classification seems inappropriate due to various overlapping of species (Lam and Bakhuizen van den Brink 1921). Based on the taxonomic revision of Philippine Callicarpa reported by Bramley (2013), members of Geunsia have been classified and showed shared characters, e.g., alternate leaves, 4-merous flowers, and shape of corolla and anthers but appeared distinct based on leaf morphology and inflorescence. To avoid confusion, he also conducted a further leaf morphological study to classify species but characters like leaf shapes appeared insufficient to successfully separate species using identification key because leaf shape is very variable across its distribution.

The taxonomy of Geunsia is extremely complex due to wide geographical distribution, species overlap, high levels of variability, and phenotypic plasticity (Kawakubo 1986; Palmer 2012). These variables were often observed through their effects on the leaf structures (Vieira et al. 2014; Li et al. 2018; Morais et al. 2019). Therefore, leaf morphology is considered the most valuable answer in identifying taxa 
particularly for species belonging to the family Lamiaceae (Balant et al. 2019). Thus, leaf description has great relevance for its species discrimination along with effective diagnostic techniques and procedures. However, leaves vary in shape features depending on their leaf tips, leaf bases, and leaf margin. Currently, no studies have identified the leaf variation among Callicarpa and Geunsia groups to further separate or combine species based on leaf shapes.

This study described for the first-time accessions of members of Geunsia and Callicarpa within the Malesian region through leaf geometric morphometrics, contributing to a better understanding of the species variation through leaf shapes. Furthermore, this study aimed to discriminate Geunsia and Callicarpa species and determine taxonomic characters to differentiate Geunsia and Callicarpa species. Thus, a promising approach to species characterization like geometric morphometrics, which allows identification of shape components (Viscosi and Cardini 2011) to assess complicated genera like Geunsia and Callicarpa is hereby introduced.

\section{MATERIALS AND METHODS}

\section{Study area}

Leaf morphology and morphometric study were carried out from selected digital herbarium samples of A, HBG, K, L, MW, NY, P, SNSB, USTH, and US (abbreviations following Index Herbariorum, Thiers) and field collections in various localities of the Philippines (Table 1). This study focuses on specimens of Geunsia and Callicarpa collected in the selected localities in the Malesian region (Figure 1). A total of 96 leaflets were sampled from 63 online accessions and 33 individual specimens from the field. Online accessions were obtained in Global Biodiversity Information Facility (GBIF) database via the web interface, while field collections were obtained from the open lowland to hill forests of the provinces of Isabela, Sorsogon, and Samar in the Philippines. Online images and descriptions were downloaded using 'Darwin Core Archive' format, which contains the URLs of the images and information in GBIF (Table S1). On the other hand, samples from the field have undergone herbarium sample collection protocol of preparation, pressing, mounting, identification, and deliberation of voucher specimen to the University of Santo Tomas Herbarium (USTH), the Philippines.

\section{Procedures: Sampling preparation and data gathering}

An initial of 96 leaflets were used to create a file for data manipulation and digitization. Based on the digital images, TPS files were created using tpsUtil32 software (Rohlf 2015). This TPS file contains the landmarks and image IDs to be used in digitizing images. In digitization, tpsDig232 software (Rohlf 2010) was used to assign landmarks on each image. Coordinates of 16 key landmarks of leaves were obtained to perform morphometric analysis (Figure 2.A). The abaxial surface of leaves was preferable because of the prominent secondary veins. Landmarks 1 and 2 were assigned, which corresponds to the junction of the petiole to the leaf tip of the primary vein (Gunz and Mitteroecker 2013).

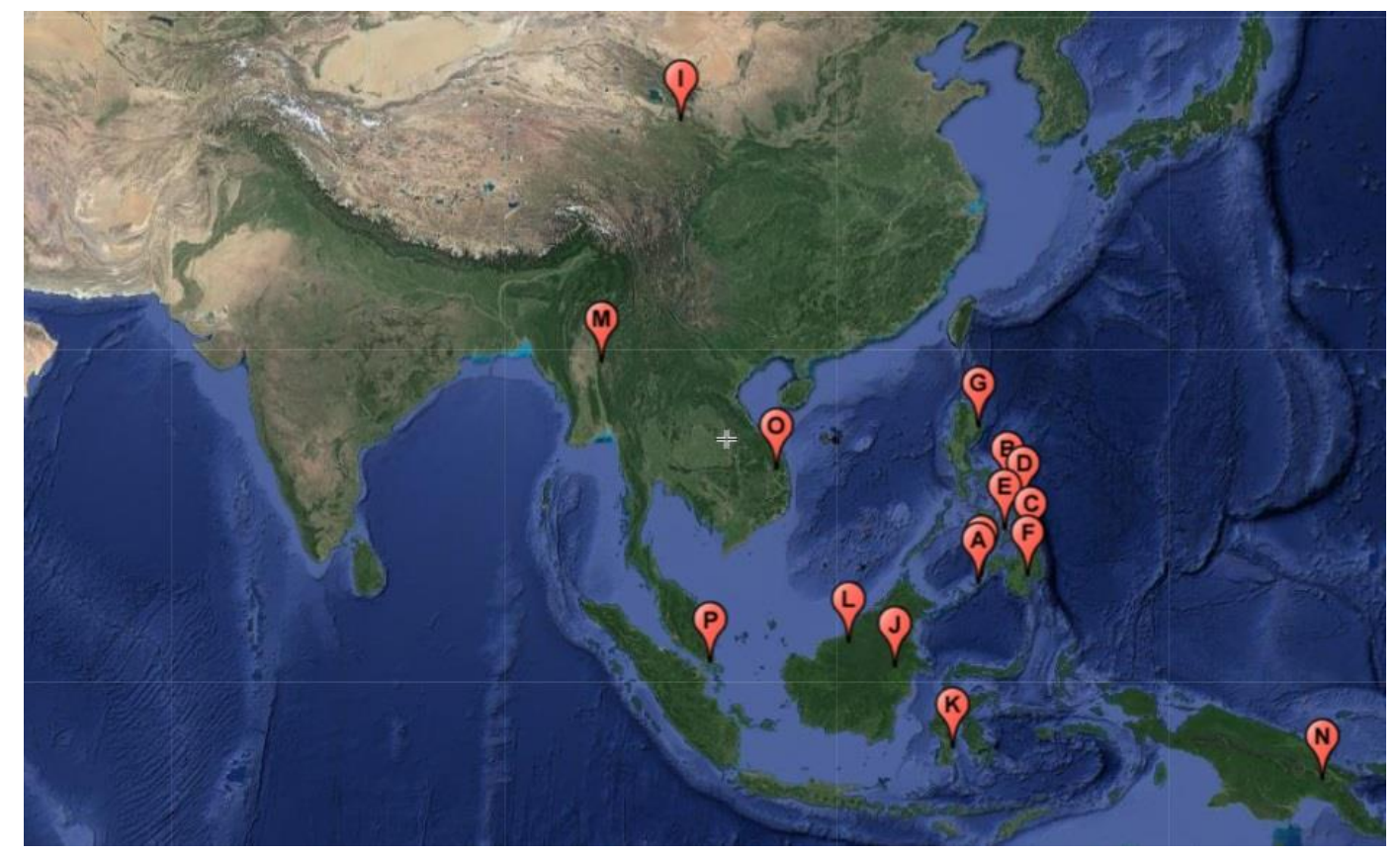

Figure 1. Localities of selected Geunsia and Callicarpa species used in this study in the Malesian region. Philippines (A-H): A. Bangsamoro (Basilan, Cotabato, Lanao, Sulu), B. Bicol (Catanduanes, Sorsogon), C. Caraga (Agusan, Dinagat, Surigao), D. Eastern Visayas (Samar, Leyte), E. Central Visayas (Cebu), F. Davao G. Isabela, H. Zamboanga Peninsula, I. China, (J-K): Indonesia J. Kalimantan K. Sulawesi, L. Malaysia, M. Myanmar, N. Papua New Guinea, O. Vietnam, P. Singapore. (Map: www.scribblemaps.com). 
Table 1. Populations and samples of Geunsia and Callicarpa groups were used in this study

\begin{tabular}{|c|c|c|c|}
\hline Species & Localities & Acc. no. & Herbaria \\
\hline \multicolumn{4}{|l|}{ Geunsia } \\
\hline \multirow[t]{7}{*}{ C. apoensis Elmer } & Indonesia & L.4316447 & Naturalis Biodiversity Center (AMD) \\
\hline & Indonesia & L.4316456 & Naturalis Biodiversity Center (AMD) \\
\hline & Davao, Philippines & HBG513403 & Herbarium Hamburgense (HBG) \\
\hline & Davao, Philippines & 103976 & The New York Botanical Garden (NY) \\
\hline & Davao, Philippines & 93867 & Harvard University Herbaria (HUH) \\
\hline & Indonesia & L332108 & Naturalis Biodiversity Center (AMD) \\
\hline & Davao, Philippines & K000194933 & Royal Botanic Gardens, Kew $(\mathrm{K})$ \\
\hline \multirow[t]{6}{*}{ C. basilanensis Merr. } & Basilan, Philippines & L2762581 & Naturalis Biodiversity Center (AMD) \\
\hline & Zamboanga, Mindanao & 714485 & National Museum of Natural History, Smithsonian Institution (US) \\
\hline & Basilan, Philippines & 119043 & National Museum of Natural History, Smithsonian Institution (US) \\
\hline & Zamboanga, Philippines & P03392618 & MNHN - Museum National d'Histoire Naturelle (P) \\
\hline & Zamboanga, Philippines & P03597180 & MNHN - Museum National d'Histoire Naturelle (P) \\
\hline & Basilan, Philippines & P03392619 & MNHN - Museum National d'Histoire Naturelle (P) \\
\hline \multirow[t]{11}{*}{ C. flavida Elmer } & Agusan, Philippines & 119053 & National Museum of Natural History, Smithsonian Institution (US) \\
\hline & Dinagat Island, Philippines & L2753770 & Naturalis Biodiversity Center (AMD) \\
\hline & Agusan, Philippines & 2270734 & Missouri Botanical Garden (MO) \\
\hline & Agusan, Philippines & 2787903 & National Museum of Natural History, Smithsonian Institution (US) \\
\hline & Agusan, Philippines & 93872 & Harvard University Herbaria (HUH) \\
\hline & Agusan, Philippines & 93873 & Harvard University Herbaria (HUH) \\
\hline & Agusan, Philippines & U0007022 & Naturalis Biodiversity Center (AMD) \\
\hline & Davao, Philippines & 119056 & National Museum of Natural History, Smithsonian Institution (US) \\
\hline & Davao, Philippines & 93875 & Harvard University Herbaria (HUH) \\
\hline & Davao, Philippines & L2753771 & Naturalis Biodiversity Center (AMD) \\
\hline & Davao, Philippines & K000194994 & Royal Botanic Gardens, Kew (K) \\
\hline \multirow[t]{8}{*}{ C. paloensis Elmer } & Sorsogon, Philippines & 2787975 & National Museum of Natural History, Smithsonian Institution (US) \\
\hline & Sorsogon, Philippines & 2787974 & National Museum of Natural History, Smithsonian Institution (US) \\
\hline & Palo, Leyte & 103990 & The New York Botanical Garden (NY) \\
\hline & Palo, Leyte & 93883 & Harvard University Herbaria (HUH) \\
\hline & Sulawesi, Indonesia & L2757220 & Naturalis Biodiversity Center (AMD) \\
\hline & Sulu, Philippines & P03598409 & MNHN - Museum National d'Histoire Naturelle (P) \\
\hline & Agusan, Mindanao & K000194946 & Royal Botanic Gardens, Kew (K) \\
\hline & Agusan, Mindanao & K000194949 & Royal Botanic Gardens, Kew (K) \\
\hline \multirow[t]{11}{*}{ C. pentandra Roxb. } & Cebu, Philippines & K000248661 & Royal Botanic Gardens, Kew (K) \\
\hline & Kalimantan, Indonesia & K00094945 & Royal Botanic Gardens, Kew (K) \\
\hline & Davao, Philippines & K000194931 & Royal Botanic Gardens, Kew (K) \\
\hline & Papua New Guinea & K000194977 & Royal Botanic Gardens, Kew (K) \\
\hline & Kalimantan, Indonesia & K000249402 & Royal Botanic Gardens, Kew (K) \\
\hline & Surigao, Philippines & K000194992 & Royal Botanic Gardens, Kew (K) \\
\hline & Davao, Philippines & K000194930 & Royal Botanic Gardens, Kew (K) \\
\hline & Cebu, Philippines & K000248662 & Royal Botanic Gardens, Kew (K) \\
\hline & Singapore & K001114363 & Royal Botanic Gardens, Kew (K) \\
\hline & Samar, Philippines & JDS008 & University of Santo Tomas, Philippines (USTH) \\
\hline & Samar, Philippines & K000674786 & Royal Botanic Gardens, Kew $(\mathrm{K})$ \\
\hline \multirow[t]{9}{*}{ C. ramiflora Merr. } & Catanduanes, Philippines & U0040805 & Naturalis Biodiversity Center (AMD) \\
\hline & Leyte, Philippines & 2788026 & National Museum of Natural History, Smithsonian Institution (US) \\
\hline & Leyte, Philippines & L2762376 & Naturalis Biodiversity Center (AMD) \\
\hline & Catanduanes, Philippines & 2788025 & Naturalis Biodiversity Center (AMD) \\
\hline & Leyte, Philippines & L2754623 & Naturalis Biodiversity Center (AMD) \\
\hline & Zamboanga, Philippines & 119049 & National Museum of Natural History, Smithsonian Institution (US) \\
\hline & Lanao del Sur, Philippines & 119084 & National Museum of Natural History, Smithsonian Institution (US) \\
\hline & Lanao Lake, Mindanao & M0111549 & Staatliche Naturwissenschaftliche Sammlungen Bayerns (SNSB) \\
\hline & Catanduanes, Philippines & P03598371 & MNHN - Museum national d'Histoire Naturelle (P) \\
\hline \multirow[t]{6}{*}{ C. surigaensis Merr. } & Surigao, Philippines & 2788017 & Smithsonian Institution, NMNH, Botany (US) \\
\hline & Surigao, Philippines & 2788016 & National Museum of Natural History, Smithsonian Institution (US) \\
\hline & Surigao, Philippines & 1269210 & Smithsonian Institution, NMNH, Botany (US) \\
\hline & Surigao, Philippines & 1269211 & Smithsonian Institution, NMNH, Botany (US) \\
\hline & Surigao, Philippines & 1107985 & Smithsonian Institution, NMNH, Botany (US) \\
\hline & Surigao, Philippines & P03598359 & MNHN - Museum national d'Histoire Naturelle (P) \\
\hline \multicolumn{4}{|r|}{ 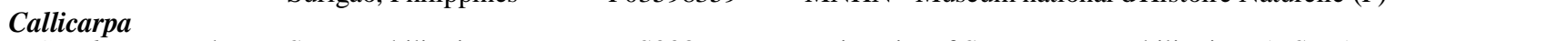 } \\
\hline C. arborea Roxb. & Samar, Philippines & JES008 & University of Santo Tomas, Philippines (USTH) \\
\hline C. erioclona Schauer & Sorsogon, Philippines & SOR006 & University of Santo Tomas, Philippines (USTH) \\
\hline C. pedunculata R.Br. & Isabela, Philippines & JDS001 & University of Santo Tomas, Philippines (USTH) \\
\hline \multirow[t]{7}{*}{ C. rubella Lindl. } & Vietnam & MW0757612 & Lomonosov Moscow State University (MW) \\
\hline & Vietnam & 2808046 & The New York Botanical Garden (NY) \\
\hline & Vietnam & P00991455 & MNHN - Museum National d'Histoire Naturelle (P) \\
\hline & Myanmar & 2648823 & The New York Botanical Garden (NY) \\
\hline & China & 2787428 & National Museum of Natural History, Smithsonian Institution (US \\
\hline & Myanmar & 3231815 & The New York Botanical Garden (NY) \\
\hline & Malaysia & L0534846 & Smithsonian Institution, NMNH, Botany (US) \\
\hline
\end{tabular}




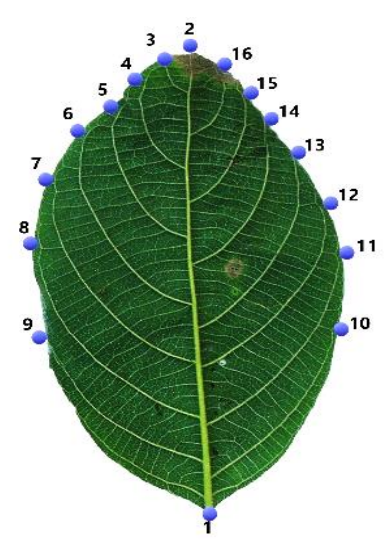

A

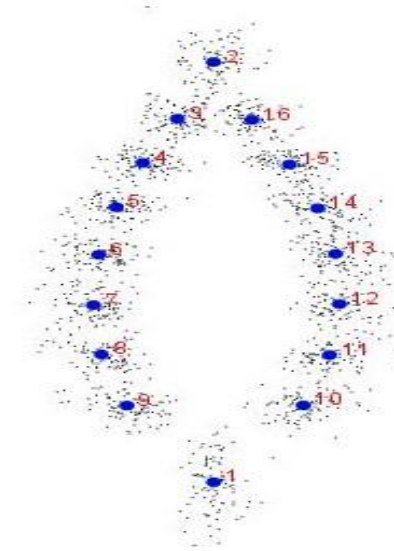

B
Figure 2. Leaf morphometrics. A. Abaxial surface with primary landmarks (1-2) and semilandmarks (3-16) of $C$. pentandra (Photo: University of Minnesota Bell Museum (2021). Bell Museum plants. Occurrence dataset https://doi.org/10.15468/bihrxd accessed via GBIF.org on 202108-02. https://www.gbif.org/occurrence/2265568305), B. Mean landmarks (large dots) and individual landmarks in all samples of Geunsia and Callicarpa (small dots) before elimination of outliers

Fourteen semi landmarks of secondary veins were assigned to represent changes around the leaf margin. The number of semi landmarks determined in a study depends on the complexity of curves and the position of the veins (Gunz and Mitteroecker 2013). After assigning landmarks, consensus files were generated from landmark images used in the populations of Geunsia and Callicarpa species. To create a data set, the TPS file was imported into the software package MorphoJ (Klingenberg 2011). The Procrustes fit was generated, showing the mean and landmark position for individual configurations in all samples (Figure 2.B). A preliminary transformation was conducted by eliminating outliers within the scatter plot generated during Principal Component Analysis (PCA) (Hotelling 1933). In this study, PC1 and PC2 were used to identify outliers. Potential outliers were detected by identifying data points separated from the main scatter plot ellipses (Viscosi and Cardini 2011) and cross-checked for further leaf shape deviation using MorphoJ. Outliers were deleted from the data before the computation of the mean leaf configurations of the final dataset. Outliers may contain noise that was obtained from the digital images and may affect the accuracy of the study (Du et al. 2007).

\section{Data analysis}

\section{Multivariate analysis of outliers}

In the study between Geunsia and Callicarpa groups, the analysis led to the identification of 12 outliers out of 96 data points of leaves (12.50\%) observed in PC1 and PC2. Geunsia and Callicarpa have percentage values of outliers, $9.43 \%$, and $16.28 \%$, respectively. The new set of samples consisted of 84 leaflets from 36 and 48 leaflets of Callicarpa and Geunsia, respectively. Likewise, a separate analysis of outliers was done exclusively for the species of Geunsia, which led to the identification of 13 outliers out of 53 leaves $(25 \%)$ thereby creating a new dataset of 40 leaflets. All the outliers identified through this procedure were eliminated from the data matrices of landmarks for each sample. All samples were separately extracted to create new datasets for subsequent multivariate analysis of intergeneric and interspecific classification (Figure 3.A-B).

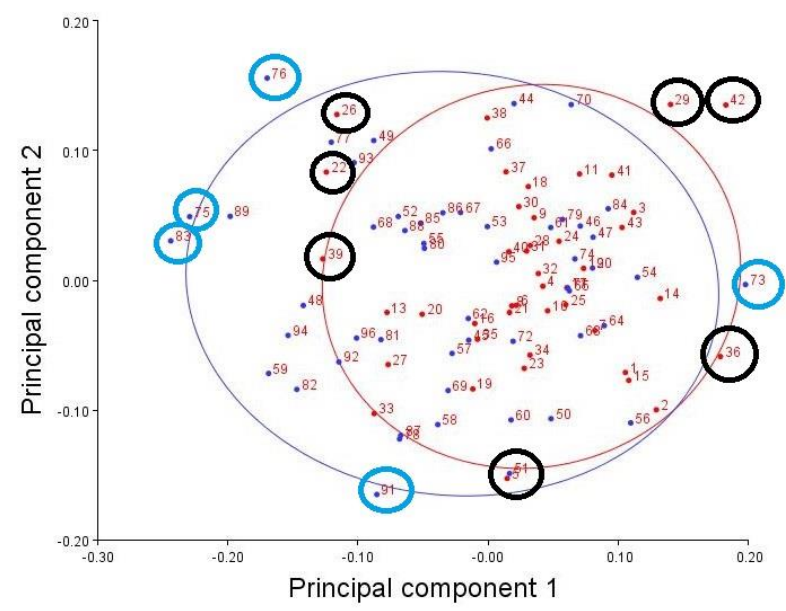

A

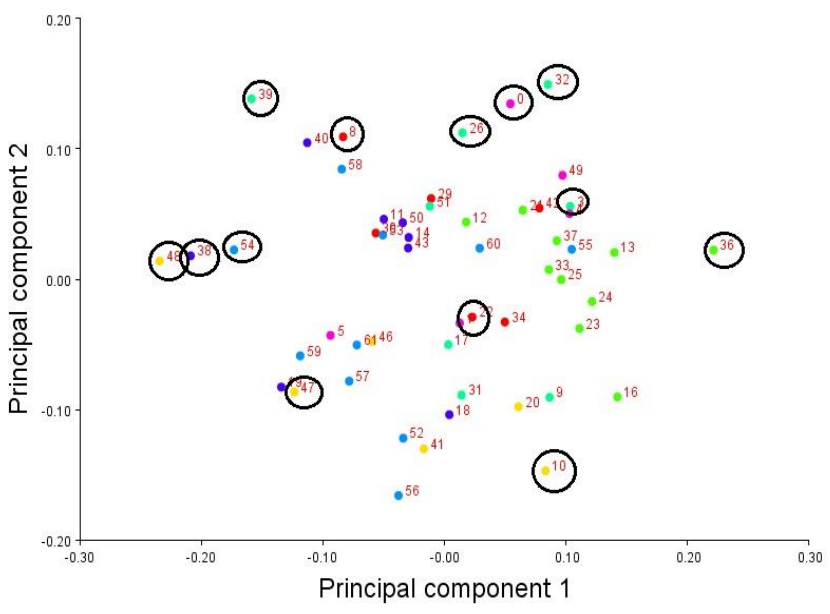

B

Figure 3. Selection of outliers (encircled) among samples of: A. Geunsia and Callicarpa (black: Callicarpa; blue: Geunsia; B. combined seven species of Geunsia (black: randomly selected species of Geunsia) 
Multivariate analysis of leaf shape variability

The new dataset was subjected to various statistical analyses like PCA, Canonical Variate Analysis (CVA), and Discriminant Function Analysis (DFA). PCA was used to check the total leaf shape variation of 84 individuals of combined Geunsia and Callicarpa samples and 40 individuals of the Geunsia species. PCA treats all configurations for each sample regardless of species or any form of group classification into one population. Principal component axes or shape trends were visualized through thin-plate spline reconstructions of the shapes which correspond to the leaf changes of the significant PCs. Likewise, Eigenvalues were included to measure the amount of variation explained on each PCs. In this study, data were assessed between Geunsia and Callicarpa groups and within the treatment group. CVA was used to classify samples into known groups by measuring the strength of the relationship based on the highest correlated calculation (Klingenberg 2011). The canonical variates (CVs) show which axes best discriminate between the group and within-group variation (Zelditch et al. 2004). The discrimination was best observed when using a scatterplot which allows separation of species based on treatment groups assigned. In this study, CVA was performed to discriminate samples of Geunsia based on species. Procrustes and Mahalanobis distances were also used to show patterns of morphological similarity between groups of Callicarpa and Geunsia species and among members of Geunsia through pairwise comparison. Mahalanobis Distance (MD) measures the distance between a distinct point of the specimen relative to the mean position of all points of an object. In this case, one can estimate the degree of a specimen to belong to a group whose mean is the closest (Viscosi and Cardini 2011). In comparison, Procrustes Distance (PD) refers to the measure of the absolute magnitude of shape deviation based on mean landmark changes of two samples to quantify the similarity and differences (Bookstein 1996). Likewise, a crossvalidation test (permutation test with 10,000 rounds) was performed to evaluate the classification accuracy of Geunsia and Callicarpa and among members of Geunsia based on MD. The Procrustes ANOVA (Analysis of Variance) was also used for testing the shape differences among the samples of the Geunsia group if statistically significant $(\mathrm{p} \leq 0.05)$. All analyses were performed using the software MorphoJ (Klingenberg 2011).

\section{RESULTS AND DISCUSSION}

\section{Leaf geometric morphometrics between Geunsia and Callicarpa species}

Significant variations from all 84 samples mostly occurenced in the first four principal components (PC1, PC2, PC3, and PC4) with a cumulative variance of $77.24 \%$ (Table 2). The proportion of variance method to retain a considerable number of PCs which accounts from the highest percentage to $5-10 \%$ of the total variance was considered, whereby the proportion of variance is obtained by dividing eigenvalue for the component of interest by total eigenvalues of the correlation matrix (Jackson 1993). All Geunsia and Callicarpa species were united inside their respective ellipses (Figure 4.A-B). However, the two ellipses in both diagrams showed an overlap which suggests that leaf shapes similarities exist between groups. The PC1 score $(31.49 \%)$ represents changes in the width of the leaf resulting in ovate to narrowly ovate leaves (Figure 4.C). The PC2 score $(23.31 \%)$ represents a change in the leaf shape showing a minimal extension of the apical and distal region of the leaf. While PC3 and PC4 both constitute a low score, $14.19 \%$, and $8.26 \%$, respectively, but the changes became conspicuous due to asymmetric variation on the leaf shape mostly found either on one side of bases or tips of the leaves.

Comparisons between the groups were performed using the Canonical Variate Analysis (CVA), wherein the first canonical variate (CV1) was accounted for $100 \%$ of the total variance (Table 3). MD and PD were also obtained by pairwise comparison between the Geunsia and Callicarpa and showed highly significant differences (permutation 10,000 rounds in MorphoJ: $\mathrm{P}<.0001$ ) of 1.7965 and 0.0569 , respectively. A significant difference in the $P$-values from the permutation test for $\mathrm{MD}$ and $\mathrm{PD}$ among groups were $<.0001$ and 0.0024 , respectively. Most of the shape changes between the groups generally accounted for the width of the leaf. Despite this, the result of Discriminant Analysis (DA) (Figure 4.D, Hotelling's $\mathrm{T}^{2}=66.39, P$-value $=$ 0.0708) in comparing the two taxa showed that leaf shape does not differentiate them sufficiently to allow distinction. Likewise, the cross-validation of correctly classified Callicarpa $(61.11 \%)$ and Geunsia $(60.42 \%)$ showed low percentage and overlap made leaf shape difference ineffective for separating genus Geunsia from Callicarpa.

Table 2. The first ten of a Principal Component Analysis (PCA) of leaf shape in 84 individuals of Callicarpa and Geunsia species

\begin{tabular}{lccc}
\hline PC & Eigenvalues & \% Variance & Cumulative \% \\
\hline 1 & 0.00585 & 31.488 & $31.488^{*}$ \\
2 & 0.00433 & 23.306 & $54.795^{*}$ \\
3 & 0.00264 & 14.185 & $68.98^{*}$ \\
4 & 0.00154 & 8.263 & $77.243^{*}$ \\
5 & 0.00088 & 4.748 & 81.991 \\
6 & 0.00076 & 4.097 & 86.088 \\
7 & 0.00057 & 3.073 & 89.16 \\
8 & 0.00043 & 2.337 & 91.497 \\
9 & 0.00029 & 1.544 & 93.042 \\
10 & 0.00026 & 1.379 & 94.421 \\
\hline
\end{tabular}

*Note: Only the first four are significant according to the proportion of variance with $5-10 \%$ of the total variance. Eigenvalues are derived from a matrix of 84 Procrustes-aligned configurations of 16 landmarks. 


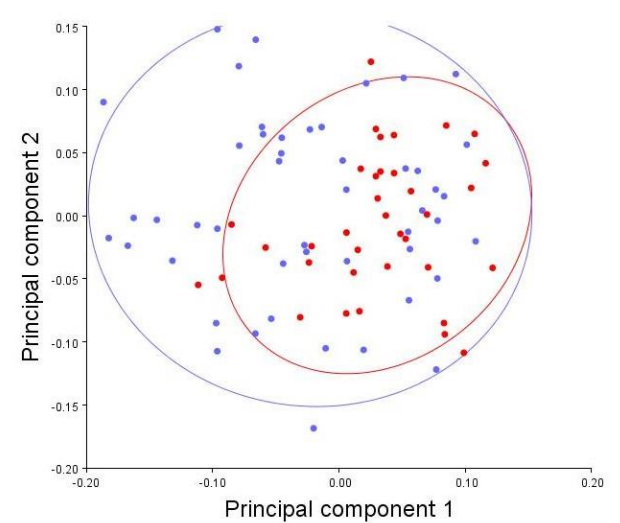

A
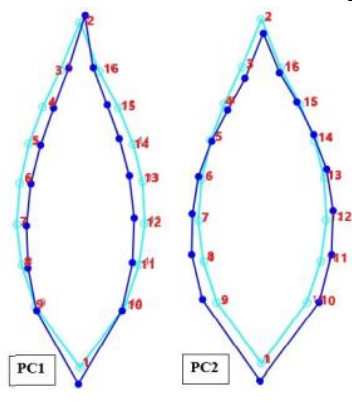

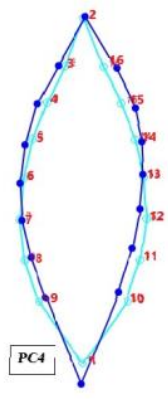

C

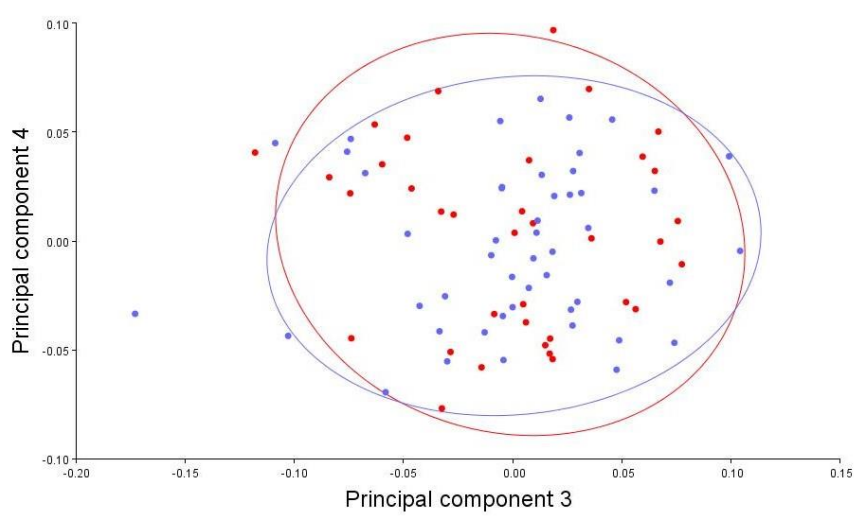

B

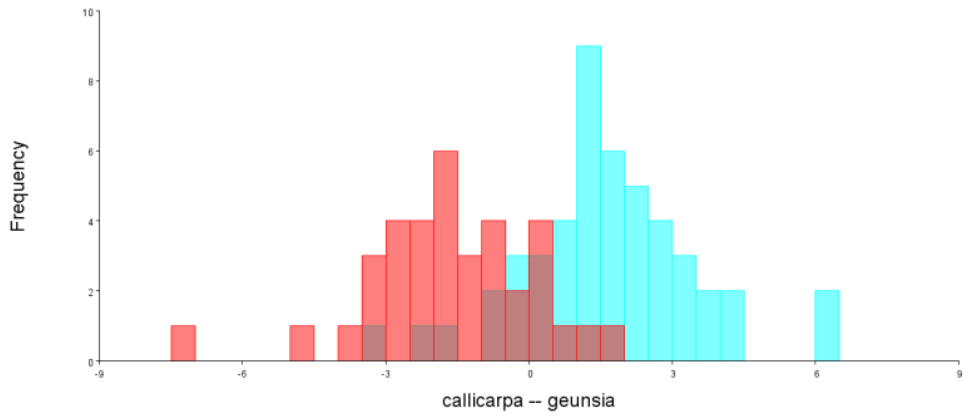

D

Figure 4. The Principal Component Analysis (PCA). A-B. Scatter plot of 4 PCs in the leaf of all 84 individuals of Geunsia (blue) and Callicarpa (red) group of Callicarpa, C. Axis components of PC1, PC2, PC3, and PC4 showing the variation in leaf shape, D. Discriminant analysis (DA) between Geunsia and Callicarpa (red bars: Callicarpa; blue bars: Geunsia) Hotelling's $\mathrm{T}^{2}=66.39, P=$ 0.0708. Computed in Morpho J (Klingenberg 2011).

Table 3. Differences in leaf shape of Callicarpa species between groups of Geunsia and Callicarpa species analyzed with Canonical Variate Analysis (CVA), percentage of correctly classified specimens, and variation among groups, scaled by the inverse of the withingroup variation

\begin{tabular}{lllccccc}
\hline Geunsia & Callicarpa & $\begin{array}{c}\text { \% of } \\
\text { correctly } \\
\text { classified }\end{array}$ & $\begin{array}{c}\text { P values } \\
\text { Mahalanobis } \\
\text { Distance }\end{array}$ & $\begin{array}{c}\text { P values } \\
\text { Proscrustes } \\
\text { Distance }\end{array}$ & Eigenvalues & $\begin{array}{c}\text { Variance } \\
\%\end{array}$ & $\begin{array}{c}\text { Cumulative } \\
\%\end{array}$ \\
\hline $\begin{array}{l}\text { Geunsia } \\
\text { Callicarpa }\end{array}$ & $\mathbf{1 . 7 9 6 5}$ & $\underline{0.0569}$ & $\begin{array}{l}60 \%(29 / 48) \\
61 \%(22 / 36)\end{array}$ & $<.0001$ & 0.0024 & PC1 & 100 \\
\hline
\end{tabular}

Note: Mahalanobis Distances (bold, underlined) and Procrustes Distances (narrow, underlined). $P$-values based on permutation 10,000 rounds in MorphoJ: $P<0.0001)$

The morphometric approach confirmed leaf shape variations between Geunsia and Callicarpa (Figure 4.C). In addition, the extremely reconstructed outlines along the axes and the scatter plot (Figure 4.A-B) showed that Geunsia and Callicarpa correspond to the ovate to narrowly ovate shape pattern. This pattern is supported by collections of the field and herbarium (Bramley 2009, 2013). However, species discrimination based on CVA and DA analyses does not show a reliable pattern that distinguishes the two genera (Figure 4.D). Thus, a weak indication of leaf shape differentiation between the two taxa suggests a tendency for some samples to be less distant from the other, resulting in an overlap in the intergeneric comparison. According to Adebowale et al. (2012), an overlap in morphological characters like leaf shape in the application of geometric morphometrics could have environmental and genetic explanations. Moreover, an overlap manifested in the intergeneric assessment is possibly due to the presence of hybrid in the individual samples in species occupying similar habitat; thus similarity in leaf shape could reflect evolutionary adaptation to environmental conditions (Adebowale et al. 2012; Mirouze et al. 2012). Callicarpa has been reported to show the incidence of hybridization in several plant species (Tsukaya et al. 2003). Hence, this may affect the result of geometric morphometrics to discriminate Geunsia and Callicarpa and may underline the limitation of a single approach in solving taxonomic problems. 


\section{Leaf geometric morphometrics among members of Geunsia species}

After eliminating the outliers, the Principal Component Analysis (PCA) from all 40 samples of the Geunsia group is presented in Table 4. The PCA indicated that the first five components (PC1, PC2, PC3, PC4, and PC5) were responsible for $82.610 \%$ of the significant leaf shape variation obtained from the selected samples of Geunsia. PC1 of $33.022 \%$ showed the highest variation representing leaf tip changes from acute to attenuate and a minimal expansion of the leaf bases. PC2 (25.871\%) was responsible for width changes of leaves from narrowly ovate to ovate shape. While PC3, PC4, and PC5 of $9.417 \%, 8.175 \%$, and $6.124 \%$, respectively refer to the non-symmetric shape patterns of the leaf (Table 4, Figure 5.A). PC3 is responsible for unequal extension of the apical region with a slight curvature on its tip and a minimal contraction in the proximal part of the leaf, while PC4 and PC5 showed inconspicuous expansion in the width, distal and proximal part of the leaf.
Table 4. The Principal Component Analysis (PCA) of leaf shape in 40 individuals of Geunsia species

\begin{tabular}{lccc}
\hline PC & Eigenvalues & \% Variance & Cumulative \% \\
\hline 1 & 0.0048015 & 33.022 & $33.022^{*}$ \\
2 & 0.0037616 & 25.871 & $58.893^{*}$ \\
3 & 0.0013693 & 9.417 & $68.310^{*}$ \\
4 & 0.0011886 & 8.175 & $76.485^{*}$ \\
5 & 0.0008905 & 6.125 & $82.610^{*}$ \\
6 & 0.0006784 & 4.665 & 87.275 \\
7 & 0.0003981 & 2.738 & 90.013 \\
8 & 0.0003150 & 2.166 & 92.180 \\
9 & 0.0002201 & 1.513 & 93.693 \\
10 & 0.0001875 & 1.290 & 94.983 \\
\hline
\end{tabular}

*Note: Only the first five are significant according to the proportion of variance with $5-10 \%$ of the total variance. Eigenvalues are derived from a matrix of 40 Procrustes-aligned configurations of 16 landmarks

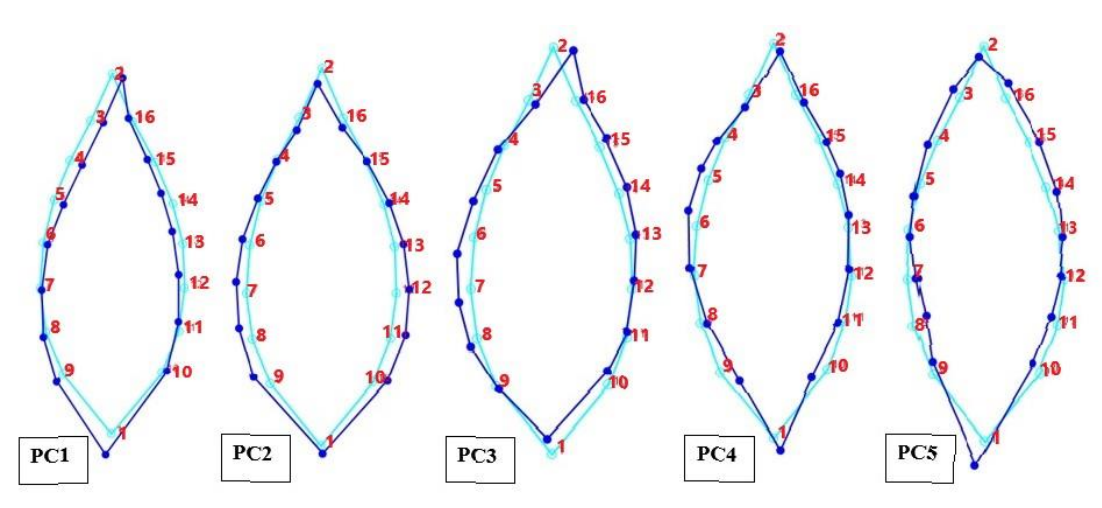

A

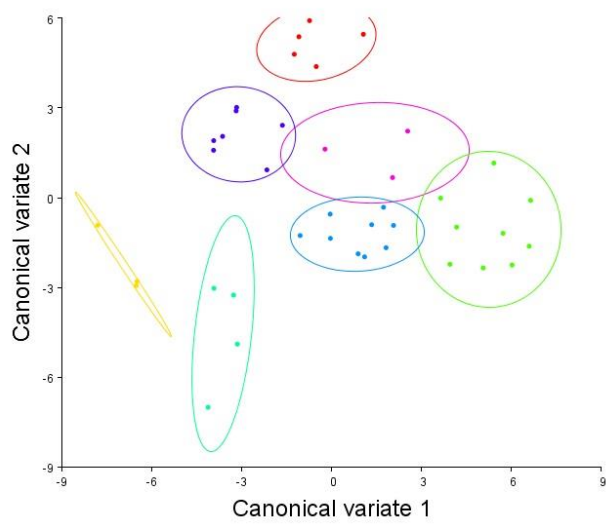

B

Figure 5. Analysis in all leaf samples of 40 individuals of Geunsia group. A. Axis components of PC1 (33.02\%), PC2 (25.87\%), PC3 (9.42\%), PC4 (8.18\%), and PC5 (6.13\%) showing the variation in leaf shape of Geunsia group; B. The canonical variate analysis (CVA)

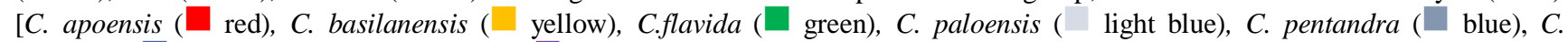
ramiflora ( $\square$ dark blue), and C. surigaensis ( $\square$ purple)].

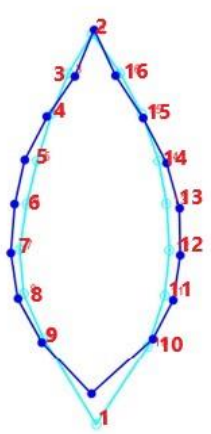

A

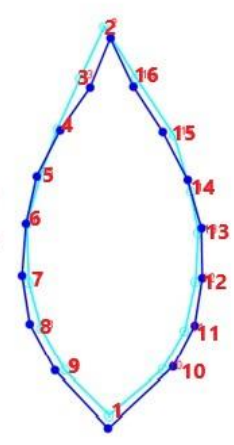

B

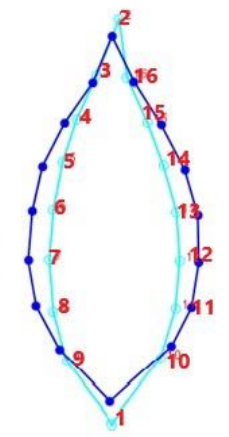

C

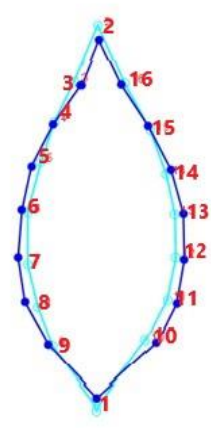

D

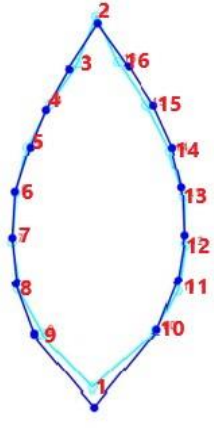

$\mathbf{E}$

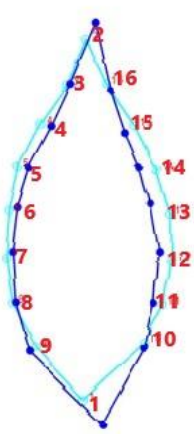

$\mathbf{F}$

Figure 6. Transformation grids illustrate the shape changes from the overall mean shape of $C$. pentandra among other members of Geunsia. A. C. apoensis, B. C. basilanensis, C. C. flavida, D. C. paloensis, E. C. ramiflora, F. C. surigaensis. Dots indicate the mean shape of $C$. pentandra and the line represents the change in leaf shape relative to the position of other members of Geunsia 
Canonical Variate Analysis (CVA) was able to generate six variables among samples of the Geunsia species (Table 5). The scatter plot of CV1 and CV2 were accounted for $68.888 \%$ of the variation and shows that all samples $(C$. basilanensis, $C$. pentandra, C. flavida, C. ramiflora, C. paloensis, C. apoensis, and $C$. surigaensis) were clearly identified and successfully placed into its distinct groups (Figure 5.B). Likewise, the MD scores were obtained, which range from 6.3015 (C. ramiflora and C. apoensis) to 12.6607 (C. flavida and $C$. basilanensis) by pairwise comparisons (Table 6). Using multivariate normal distribution, one can estimate the degree of a specimen to belong to a group whose mean is the closest (Viscosi and Cardini 2011). In this study, $C$. ramiflora and $C$. apoensis showed the nearest distance to the central point or the overall mean of data points in all samples. Furthermore, all samples used in the pairwise comparison was statistically significant in their distance relative to the centroid (Table 7). Thus, MD provided an effective and convenient way to quantitatively compare the magnitude of cluster separation in an ambiguous taxon like the Geunsia species. While PD scores ranged from 0.0684 (C. ramiflora and $C$. pentandra) to 0.1607 (C. ramiflora and $C$. flavida) also showed highly significant differences on a few samples of the Geunsia group (Table 8). Procrustes distance showed significant difference among $C$. ramiflora and $C$. flavida (<.0001), C. pentandra and $C$. flavida (0.0003), C. basilanensis and C. flavida (0.0048), C. flavida and $C$. apoensis (0.0099) and $C$. paloensis and $C$. flavida (0.0103) (Table 9). In this regard, the difference among these species could be explained by their leaf shape difference. Likewise, Procrustes ANOVA results showed significant differences among populations of Geunsia species (Table 10). Leaf shape differences among taxa were statistically significant $(P$ $=0.0082$ ), and strong clustering made overall leaf shape difference effective in separating members of Geunsia.

Table 5. Canonical variate analysis (CVA) of 40 samples of Geunsia species

\begin{tabular}{llll}
\hline CV & Eigenvalues & \% Variance & Cumulative \% \\
\hline 1 & 15.920517 & 44.200 & 44.200 \\
2 & 8.8924508 & 24.688 & 68.887 \\
3 & 4.7232715 & 13.113 & 82.000 \\
4 & 2.9410219 & 8.165 & 90.166 \\
5 & 2.0241605 & 5.620 & 95.785 \\
6 & 1.5181756 & 4.215 & 100.000 \\
\hline
\end{tabular}

Table 6. Mahalanobis distances among groups showed differences in leaf shape of Geunsia species among groups based on species analyzed with Canonical Variate Analysis (CVA)

\begin{tabular}{|c|c|c|c|c|c|c|}
\hline & APO & BAS & FLA & PAL & PEN & RAM \\
\hline$\overline{\text { BAS }}$ & 10.5466 & & & & & \\
\hline FLA & 8.8952 & 12.6607 & & & & \\
\hline PAL & 10.5837 & 6.9693 & 10.025 & & & \\
\hline PEN & 7.9616 & 9.9683 & 6.4654 & 7.2779 & & \\
\hline RAM & 6.3015 & 8.2473 & 9.4752 & 7.7460 & 6.3831 & \\
\hline SUR & 8.3237 & 11.801 & 8.3311 & 10.0538 & 6.7831 & 8.0964 \\
\hline
\end{tabular}

Note: C. apoensis (APO), C. basilanensis (BAS), C. flavida (FLA), C. paloensis (PAL), C. pentandra (PEN), C. ramiflora (RAM), and C. surigaensis (SUR).

Table 7. $P$-values from permutation tests ( 10000 permutation rounds) for Mahalanobis Distances among groups

\begin{tabular}{|c|c|c|c|c|c|c|}
\hline & APO & BAS & FLA & PAL & PEN & RAM \\
\hline BAS & 0.0128 & & & & & \\
\hline FLA & 0.0002 & 0.0036 & & & & \\
\hline PAL & 0.0044 & 0.0342 & 0.0004 & & & \\
\hline PEN & 0.0001 & 0.0014 & 0.0001 & 0.0006 & & \\
\hline RAM & $<.0001$ & 0.0083 & $<.0001$ & 0.0029 & $<.0001$ & \\
\hline SUR & 0.0071 & $<.0001$ & 0.0048 & 0.0188 & 0.0039 & 0.0044 \\
\hline
\end{tabular}

Note: All values were statistically significant. (permutation 10,000 rounds in MorphoJ: $P<0.0001$ )

Note: see the previous table (abbreviations)

Table 8. Procrustes Distances among groups showed differences in leaf shape of Geunsia species among groups based on species analyzed with canonical variate analysis (CVA)

\begin{tabular}{lllllll}
\hline & APO & BAS & FLA & PAL & PEN & RAM \\
\hline BAS & 0.1223 & & & & & \\
FLA & 0.1006 & 0.1447 & & & & \\
PAL & 0.0805 & 0.067 & 0.0998 & 0.0766 & 0.0684 & 0.1149 \\
PEN & 0.095 & 0.0764 & 0.1424 & 0.0995 & 0.1176 & \\
RAM & 0.0831 & 0.1202 & 0.1607 & 0.0929 & & \\
SUR & 0.0842 & 0.1463 & 0.99 & & & \\
\hline
\end{tabular}

Note: see the previous table (abbreviations) 
Table 9. $P$-values from permutation tests (10000 permutation rounds) for Procrustes Distances among groups

\begin{tabular}{lllllll}
\hline & APO & BAS & FLA & PAL & PEN & RAM \\
\hline BAS & 0.0547 & 0.0048 & & & & \\
FLA & 0.0099 & 0.6587 & 0.0103 & & & \\
PAL & 0.3414 & 0.5676 & 0.0003 & 0.4064 & 0.2913 & 0.1526 \\
PEN & 0.1140 & 0.0802 & $<.0001$ & 0.1056 & 0.2192 & \\
RAM & 0.1689 & 0.308 & 0.2708 & 0.5625 & & \\
SUR & 0.7019 & .
\end{tabular}

Note: Statistically significant (bold) and not significant (narrow) (permutation 10,000 rounds in MorphoJ: $P<0.0001$ )

Note: see the previous table (abbreviations)

Table 10. Shape, procrustes ANOVA among Geunsia species

\begin{tabular}{llllll}
\hline Source & SS & MS & Df & F & P \\
\hline Between Treatments & 636.970461 & 106.161744 & 6 & 3.53 & 0.0082 \\
Within Treatments & 991.703317 & 30.051616 & 33 & & \\
\hline Note: $S S=$ the sum of squares; MS = mean of the square; $\mathrm{Df}=$ degrees of freedom; $\mathrm{F}=$ F-value; $P=P$-value &
\end{tabular}

Note: $\mathrm{SS}=$ the sum of squares; $\mathrm{MS}=$ mean of the square; $\mathrm{Df}=$ degrees of freedom; $\mathrm{F}=\mathrm{F}$-value; $P=P$-value

According to Lam and Bakhuizen van den Brink (1921 and Bramley (2013), C. pentandra shares morphological characters within the species of the Geunsia group. For example, a closely related species, $C$. flavida shares morphological characters like alternate leaves, 4-5-merous flowers, and the shape of corolla and anthers with $C$. pentandra. In a pairwise comparison of $C$. pentandra with other members of Geunsia, C. flavida showed the nearest distance to the centroid $(\mathrm{MD}=6.4654)$ relative to $C$. pentandra. All specimens of the two taxa were clustered and showed distinct groups. Similarly, PD (0.1424) (Figure 6.C) reveals a significant difference $(P=0.0003)$ (Table 9$)$ between $C$. pentandra and $C$. flavida. The two taxa show conspicuous leaf shape variations represented by width expansion from ovate to narrowly ovate. Thus, this study showed that leaf morphometrics has great relevance in the discrimination of species belonging to Geunsia group.

The study of seven Geunsia species using geometric morphometric analyses uncovered important leaf shape characters to discriminate species. The transformation grids' shape changes from the overall mean shape confirmed that leaf tips, leaf bases, and width expansion are the main diagnostic characters (Figure 5.A). This also proved that symmetric variations play a major role in determining leaf shape among Geunsia species. As symmetric variations dominate overall changes in the leaf shape, asymmetrical variations were also observed among the Geunsia species showing a left-right pattern at the basal and apical ends of the leaves (Figure 5.A). Fluctuating Asymmetry (FA) (van Valen 1962) may exist in Geunsia samples, whereas they normally exist as bilaterally symmetrical on leaf shapes. FA usually occurs when species from the same population show abnormal growth resulting in unequal development, leading to asymmetrical morphological characters (Leary and Allendorf 1989). Several studies linked FA with environmental and genomic factors that may affect an organism's overall development (Cowart and Graham 1999; Mal 2002). Likewise, the result of the CVA analysis in comparing the species of Geunsia showed that leaf shape discriminated them sufficiently to allow identification. At the same time, MD and PD among groups of Geunsia species analyzed with CVA identify species that are closely related to each other based on leaf shape. It reveals that leaf shape showed to be a stable character and informative on the phylogenetic and evolutionary relationship of the Geunsia species.

In conclusion, geometric morphometric analysis of leaf shapes was highly reliable and could be used as an additional method to discriminate members of the genus Geunsia. The existence of morphological distinction in leaf variations, such as acute to attenuate leaf tips and ovate to narrowly ovate leaf shapes can be useful in grouping members of Geunsia. Leaf characters like leaf shapes and leaf tips were recognized as important diagnostic characters in the study of Geunsia species. This method also allows complicated species like $C$. pentandra to distinguish and identify their relationship with other members of the Geunsia group. This study can be a precursor for any future morphological, environmental and genomic analysis to investigate the relationship of the members of Geunsia with its closely related species like members of the genus Callicarpa. Future morphological studies on landmarkbased geometric morphometric analysis of leaf shape involving a larger number of samples are encouraged in the study of interspecific and intergeneric classification.

\section{ACKNOWLEDGEMENTS}

The authors would like to thank the curators of A, HBG, K, L, MW, NY, P, SNSB, US, and USTH and the Global Biodiversity Information Facility (GBIF) for allowing us to access their digital collections for study. We thank the curator of the University of Santo Tomas (USTH) for giving us accessions to our specimens. Likewise, we would like to thank the Department of Environment and Natural Resources (DENR) for granting us the gratuitous permit to collect specimens in Isabela, Samar, and 
Sorsogon province. Lastly, the first author also would like to thank the Commission on Higher Education (CHEd) for the Scholarship and Dissertation grant.

\section{REFERENCES}

Adebowale A, Nicholas A, Lamb J, Naidoo Y. 2012. Elliptic fourier analysis of leaf shape in southern African Strychnos section Densiflorae (Loganiaceae). Bot J Linn Soc 170 (4): 542-553. DOI: 10.1111/j.1095-8339.2012.01308.x

Balant M, Glasnović P, Fišer Pečnikar Ž, Clementi M, Surina B. 2019. In search of an identity for Salvia bertolonii (Lamiaceae). Phytotaxa 413 (2): 117-136. doi: 10.11646/phytotaxa.413.2.2

Blume CL. 1823. Catalogus van Eenige der Merkwaardigste Zoo in- Als Uit-Heemsche Gewassen, te Vinden in's Lands Plantentuin te Buitenzorg, Batavia.

Bookstein FL. 1996. Combining the tools of geo- metric morphometrics. In: Marcus LF, Corti M, Loy A, Naylor GJP, Slice DE (eds) Advances in Morphometrics. Plenum, New York. DOI: 10.1007/9781-4757-9083-2_12

Bramley G. 2009. The genus Callicarpa (Lamiaceae) on Borneo. Bot J Linn Soc 159 (3): 416-455. DOI: 10.1111/j.1095-8339.2009.00907.x

Bramley G. 2011. Distribution patterns in Malesian Callicarpa (Lamiaceae). Gard Bull Singapore 63 (1 \& 2): 287-298.

Bramley G. 2013. The genus Callicarpa (Lamiaceae) in the Philippines. Kew Bull 68 (3): 369-418. DOI: 10.1007/s12225-013-9456-y

Cantino PD. 1992. Evidence for a polyphyletic origin of the Labiatae. Ann Missouri Bot Gard 79 (2): 361-379. DOI: 10.2307/2399774

Cowart NM, Graham JH. 1999. Within- and among individual variation in fluctuating asymmetry of leaves in the fig (Ficus carica L.). Int $\mathbf{J}$ Plant Sci 160 (1): 116-121. DOI: 10.1086/314104

Danila J, Alejandro GJD. 2020. Pollen morphology and infrageneric classification of selected Callicarpa species (Lamiaceae) from the Philippines and Borneo. Biodiversitas 21 (12): 5736-5746. DOI: $10.13057 /$ biodiv/d211234.

Du JX, Wang XF, Zhang GJ. 2007. Leaf shape-based plant species recognition. Appl Math Comput 185 (2): 883-893. DOI: 10.1016/j.amc.2006.07.072

Govaerts R, Paton AJ, Harvey Y, Navarro T. 2007. World Checklist of Lamiaceae. The Board of Trustees of the Royal Botanic Gardens, Kew. http://www.kew.org/wcsp

Gunz P, Mitteroecker P. 2013. Semilandmarks: a method for quantifying curves and surfaces. Hystrix Ital J Mammal 24 (1): 103-109

Harley RM, Atkins S, Budantsev AL, Cantino PD, Conn BJ, Grayer R, Harley MM, de Kok RPJ, Krestovskaja T, Morales R, Paton AJ, Ryding O, Upson T. 2004. Labiatae. In: Kubitzki K (ed) The Families and Genera of Vascular Plants, Vol. 4. SpringerVerlag, Berlin.

Hotelling H. 1933. Analysis of a complex of statistical variables into principal components. J Educ Psychol 24 (6): 417. DOI: $10.1037 / \mathrm{h} 0071325$

IPNI. 2021. International Plant Names Index. Published on the Internet http://www.ipni.org, The Royal Botanic Gardens, Kew, Harvard University Herbaria \& Libraries and Australian National Botanic Gardens.

Jackson DA. 1993. Stopping rules in principal components analysis: A comparison of heuristical and statistical approaches. Ecology 74 (8): 2204-2214. DOI: $10.2307 / 1939574$

Kawakubo N. 1986. Morphological variation of three endemic species of Callicarpa (Verbenaceae) in the Bonin (Ogasawara) Islands. Plant Species Biol 1 (1): 59-68. DOI: 10.1111/j.1442-1984.1986.tb00015.x
Klingenberg CP. 2011. MORPHOJ: An integrated software package for geometric morphometrics. Mol Ecol Resour 11 (2): 353-357. DOI: 10.1111/j.1755-0998.2010.02924.x

Lam HJ. 1919. The Verbenaceae of the Malayan Archipelago. de Waal, Groningen.

Lam HJ, Bakhuizen van den Brink RC. 1921. Revision of the Verbenaceae of the Dutch East-Indies and surrounding countries. Bull Jard Bot Série III 3: 1-116 \& I-III.

Leary RF, Allendorf FW. 1989. Fluctuating asymmetry as an indicator of stress: implications for conservation biology. Trends Ecol Evol 4 (7): 214-217. DOI: 10.1016/0169-5347(89)90077-3

Li Y, Liu Y, Song J, Zhang R, Yan Y, Wang Y, Du FK. 2018. Geometric morphometric analyses of leaf shapes in two sympatric Chinese oaks: Quercus dentata Thunberg and Quercus aliena Blume (Fagaceae). Ann For Sci 75 (4): 1-12. DOI: 10.1007/s13595-018-0770-2

Mal TK, Uveges JL, Turk KW. 2002. Fluctuating asymmetry as an ecological indicator of heavy metal stress in Lythrum salicaria. Ecol Indic 1 (3): 189-195. DOI: 10.1016/S1470-160X(02)00004-3

Mirouze E, Staquet A, Vezy R. 2012. Morphometric and morphological analysis of leaves in two species of Araceae: Montrichardia linifera and Montrichardia arborescens among different French Guiana populations. J Ecofog 3: 1-15.

Moldenke HN. 1982. Additional notes on the genus Geunsia. Phytologia 50: 143-151.

Morais DV de, Nunes LA, Mata VP da, Costa MAP de C, Sodré G da S, Carvalho CAL de. 2019. Leaf geometric morphometrics among populations of Dalbergia ecastaphyllum (L.) Taub. Biosci J 35 (6): 1789-1798. DOI: 10.14393/BJ-v35n6a2019-39814

Palmer CM, Bush SM, Maloof JN. 2012. Phenotypic and developmental plasticity in plants. eLS. DOI: 10.1002/9780470015902.a0002092.pub2

POWO 2021. Plants of the World Online. Facilitated by the Royal Botanic Gardens, Kew. Published on the Internet;
http://www.plantsoftheworldonline.org/

Ridley HN. 1923. The Flora of the Malay Peninsula Vol. 2. Reeves, London. DOI: $10.2307 / 4115416$

Rohlf FJ. 2010. tpsDig, digitize landmarks and outlines, ver. 2.16. State University of New York, Stony Brook.

Rohlf FJ. 2015. tpsUtil, file utility program. version 1.61. Department of Ecology and Evolution, State University of New York, aStony Brook.

Tsukaya H, Fukuda T, Yokoyama J. 2003. Hybridization and introgression between Callicarpa japonica and C. mollis (Verbenaceae) in central Japan, as inferred from nuclear and chloroplast DNA sequences. Mol Ecol 12 (11): 3003-3011. DOI: 10.1046/j.1365-294x.2003.01961.x

van Steenis CGGJ. 1967. Miscellaneous Botanical Notes XVII: A remarkable myrmecophyte, Callicarpa saccata n. sp., from Sarawak and some allied species. Blumea 15 (1): 145-155.

van Valen L. 1962. A study of fluctuating asymmetry. Evolution 16: 125142. DOI: $10.1111 / \mathrm{j} .1558-5646.1962 . t b 03206 . x$

Vieira M, Mayo SJ, de Andrade IM. 2014. Geometric morphometrics of leaves of Anacardium microcarpum Ducke and A. occidentale L. (Anacardiaceae) from the coastal region of Piauí, Brazil. Rev Bras Bot 37 (3): 315-327. DOI: 10.1007/s40415-014-0072-3

Viscosi V, Cardini A. 2011. Leaf morphology, taxonomy and geometric morphometrics: a simplified protocol for beginners. PLoS ONE 6: e25630. DOI: 10.1371/annotation/bc347abe-8d03-4553- 875483f41a9d51ae.t0023.cn

Zelditch, ML, Swinderski DL, Sheets HD, Fink WL. 2004. Geometric Morphometric Analysis for Biologists: A Primer. Elsevier Press, San Diego. 
Table S1. Authors and URLs of the digital images obtained from online herbarium used in this study

\begin{tabular}{l} 
AUTHOR \\
\hline Bijmoer R, Scherrenberg M, Creuwels J (2021). Naturalis Biodiversity Center \\
(NL) - Botany. Naturalis Biodiversity Center. Occurrence dataset
\end{tabular}
https://doi.org/10.15468/ib5ypt accessed via GBIF.org on 2021-07-16.

GBIF.org (02 August 2021) GBIF Occurrence Download

Herbarium Hamburgense. Herbarium Hamburgense. Occurrence dataset https://doi.org/10.15468/31iaih accessed via GBIF.org on 2021-07-16.

Kennedy J (2021). Harvard University Herbaria: All Records. Harvard University Herbaria. Occurrence dataset https://doi.org/10.15468/o3pvnh accessed via GBIF.org on 2021-07-16.

MNHN, Chagnoux S (2021). The vascular plants collection (P) at the Herbarium of the Muséum national d'Histoire Naturelle (MNHN - Paris). Version 69.218. MNHN - Museum national d'Histoire naturelle. Occurrence dataset https://doi.org/10.15468/nc6rxy accessed via GBIF.org on 2021-07-16.

Orrell T, Informatics Office (2021). NMNH Extant Specimen Records. Version 1.45. National Museum of Natural History, Smithsonian Institution. Occurrence dataset https://doi.org/10.15468/hnhrg3 accessed via GBIF.org on 2021-07-16.

Ramirez J, Tulig M, Watson K, Thiers B (2021). The New York Botanical Garden Herbarium (NY). Version 1.35. The New York Botanical Garden. Occurrence dataset https://doi.org/10.15468/6e8nje accessed via GBIF.org on 2021-07-16.

Royal Botanic Gardens, Kew (2021). Royal Botanic Gardens, Kew - Herbarium Specimens. Occurrence dataset https://doi.org/10.15468/ly60bx accessed via GBIF.org on 2021-07-16.

\section{HTTP URL}

https://www.gbif.org/occurrence/2517003371 https://www.gbif.org/occurrence/2517278400, https://www.gbif.org/occurrence/2515569033 https://www.gbif.org/occurrence/2516411626 https://www.gbif.org/occurrence/2516540585 https://www.gbif.org/occurrence/2517036420 https://www.gbif.org/occurrence/2516540443 https://www.gbif.org/occurrence/2516542437 https://www.gbif.org/occurrence/2517572837 https://www.gbif.org/occurrence/2514466640

https://doi.org/10.15468/dl.9bfpye https://doi.org/10.15468/dl.kmzyh8 https://doi.org/10.15468/dl.hm7vp6 https://doi.org/10.15468/dl.be359z https://doi.org/10.15468/dl.82s3d4 https://doi.org/10.15468/dl.bnvgt7 https://doi.org/10.15468/dl.bg7525 https://doi.org/10.15468/dl.tjzn5p

https://www.gbif.org/occurrence/1699806604

https://www.gbif.org/occurrence/1999138342 https://www.gbif.org/occurrence/1999202121 https://www.gbif.org/occurrence/1999385187 https://www.gbif.org/occurrence/1998787852 https://www.gbif.org/occurrence/1999414059

https://www.gbif.org/occurrence/2270292394 https://www.gbif.org/occurrence/474634504 https://www.gbif.org/occurrence/1317659317 https://www.gbif.org/occurrence/474961514 https://www.gbif.org/occurrence/474798295 https://www.gbif.org/occurrence/474782917

https://www.gbif.org/occurrence/1852124824 https://www.gbif.org/occurrence/1852108544 https://www.gbif.org/occurrence/1322874688 https://www.gbif.org/occurrence/1843559302 https://www.gbif.org/occurrence/1843543073 https://www.gbif.org/occurrence/1318901945 https://www.gbif.org/occurrence/1317659317 https://www.gbif.org/occurrence/1318649487 https://www.gbif.org/occurrence/1852159253 https://www.gbif.org/occurrence/1317268996 https://www.gbif.org/occurrence/1322680890 https://www.gbif.org/occurrence/1322649092 https://www.gbif.org/occurrence/1852124565 https://www.gbif.org/occurrence/1852129539 https://www.gbif.org/occurrence/1852095165

https://www.gbif.org/occurrence/1929940867 https://www.gbif.org/occurrence/1929638283 https://www.gbif.org/occurrence/1929689660 https://www.gbif.org/occurrence/1928558617 https://www.gbif.org/occurrence/1928284058

https://www.gbif.org/occurrence/912176866 https://www.gbif.org/occurrence/912176860 https://www.gbif.org/occurrence/912176851 https://www.gbif.org/occurrence/912176867 
Seregin A (2021). Moscow University Herbarium (MW). Version 1.189. Lomonosov Moscow State University. Occurrence dataset

https://doi.org/10.15468/cpnhcc accessed via GBIF.org on 2021-07-16.

Solomon J, Stimmel H (2021). Tropicos Specimen Data. Missouri Botanical Garden. Occurrence dataset https://doi.org/10.15468/hja69f accessed via GBIF.org on 2021-07-16.

Staatliche Naturwissenschaftliche Sammlungen Bayerns. The Vascular Plant Collection at the Botanische Staatssammlung München. Occurrence dataset https://doi.org/10.15468/vgr4kl accessed via GBIF.org on 2021-07-16.

The Herbarium Catalogue, Royal Botanic Gardens, Kew. Published on the Internet http://www.kew.org/herbcat [accessed on 10 July 2021]

University of Minnesota Bell Museum (2021). Bell Museum plants. Occurrence dataset https://doi.org/10.15468/bihrxd accessed via GBIF.org on 2021-08-02. https://www.gbif.org/occurrence/3004116377

https://www.gbif.org/occurrence/1259567810

https://www.gbif.org/occurrence/2981260539

http://specimens.kew.org/herbarium/K000194933 http://specimens.kew.org/herbarium/ K000194994 http://specimens.kew.org/herbarium/ K000194946 http://specimens.kew.org/herbarium/ K000194949 http://specimens.kew.org/herbarium/K000248661 http://specimens.kew.org/herbarium/K00094945 http://specimens.kew.org/herbarium/K000194931 http://specimens.kew.org/herbarium/K000194977 http://specimens.kew.org/herbarium/K000249402 http://specimens.kew.org/herbarium/K000194992 http://specimens.kew.org/herbarium/K000194930 http://specimens.kew.org/herbarium/K000248662 http://specimens.kew.org/herbarium/K001114363 http://specimens.kew.org/herbarium/ K000674786

https://www.gbif.org/occurrence/2265568305 